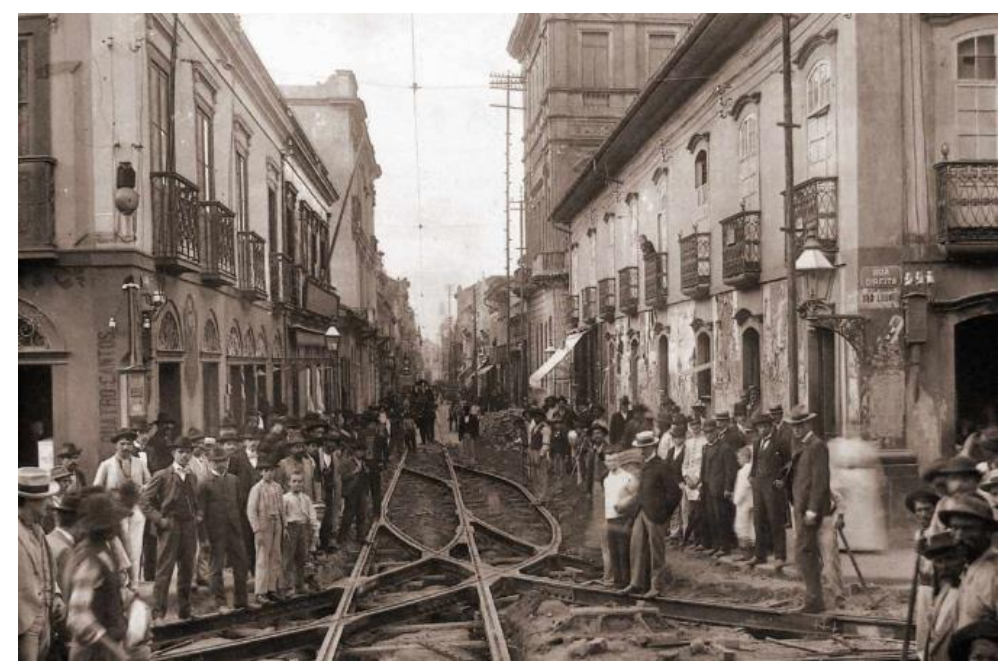

\title{
Notações sensoriais do espaço urbano em Paulicéia Desvairada (1922), de Mário de Andrade
}

\author{
Sensory notation in urban space in Paulicéia Desvairada (1922), \\ by Mário de Andrade
}

\author{
Bruna Araujo Cunha ${ }^{1}$ \\ ORCID: https://orcid.org/0000-0002-4214-7187 \\ Joelma Santana Siqueira² \\ ORCID: https://orcid.org/0000-0002-1975-887X
}

\section{Resumo:}

O artigo propõe uma análise de três poemas publicados no livro Paulicéia Desvairada (1922), de Mário de Andrade. Essa obra, assim como muitas outras do escritor paulistano, traz importantes imagens e perspectivas da cidade de São Paulo. Os poemas escolhidos, "O Domador", "Os Cortejos" e "Ruas de São Bento", permitem-nos discutir, a partir das notações sensoriais do sujeito lírico que vivencia a modernização do espaço urbano, impressões diversas da São Paulo marioandradiana.

Palavras-chave: Lírica moderna; São Paulo; Mário de Andrade; Literatura e espaço urbano.

\section{Abstract:}

This paper offers an analysis of three poems, all of which were published in the book Paulicéia Desvairada (1922), by Mário de Andrade. This work, as well as many others from the same author, elicits important imagery and perspective from São Paulo city. The chosen poems, "O Domador", "Os Cortejos" and "Ruas de São Bento", allow us to discuss, from the sensory notation of the lyrical subject who experiences the urban space modernization, various impressions from the Marioandradean São Paulo.

Key-words: Modern lyrics; São Paulo; Mário de Andrade; Literature and urban space.

\footnotetext{
${ }^{1}$ Professora substituta do Instituto Federal da Paraíba. Mestre em Estudos Literários (UFV). Doutora em Teoria e História Literária (Unicamp). E-mail: bruna.cunha@ifpb.edu.br.

2 Professora de Literatura Brasileira do curso de Letras da Universidade Federal de Viçosa (UFV). Professora efetiva do Programa de Pós-graduação em Letras da mesma instituição. E-mail: jandraus@ufv.br.
} 


\section{Considerações iniciais}

A cidade tem sido assunto frequente nos estudos literários. No ensaio "A cidade, a literatura e os estudos culturais: do tema ao problema", Renato Cordeiro Gomes (1999) ressaltou que a relação entre Literatura e experiência urbana intensificou-se na modernidade, pois a cidade tornou-se uma paisagem inevitável e mesmo quando não incorporada nos textos, faz-se presente pela sua ausência, que deixa marcas como a violência, a solidão, entre outros. O cenário da cidade é um “espaço privilegiado para as identificações culturais emergentes, para a articulação das diversas representações sociais, ou para usar um termo em alta, para a "etnificação da cultura"” (GOMES, 1999, p. 23). A cidade, espaço que tem a rua como traço forte de sua cultura, capaz de ser observada pelo viés do imaginário, que inclui a literatura, "passa a ser não só cenário, mas grande personagem de muitas narrativas, ou a presença incorporada em muitos poemas".

Considerada como a bandeira do movimento modernista, segundo João Luiz Lafetá (2004, p. 58), a publicação de Paulicéia Desvairada, em 1922, inicia na literatura brasileira a abordagem da cidade grande e o rompimento com a poética parnasiana, principalmente pelo uso do verso-livre. Problematizando a cidade grande moderna, com a presença significativa da tensão entre o "eu" e a "cidade", Paulicéia Desvairada, ou a São Paulo marioandradiana dos anos 1920, reúne poemas que fazem alusão a várias transformações urbano-industriais da cidade de São Paulo. Para tanto, "o poeta do cotidiano" recorre às ruas, praças, rios, parques, permitindo-nos lembrar de Zygmunt Baumam (2009, p. 21) quando sustenta o princípio de que "não se pode pensar em compartilhar uma experiência sem partilhar o espaço". Sendo assim, o eu-lírico faz menção aos espaços públicos e ao cotidiano urbano ao abordar a imigração, a industrialização e a modernização desenfreada da cidade.

Nessa obra modernista, carregada de objetos representativos da cidade grande, o eu-lírico não canta os elementos da modernidade, mas sim a relação do sujeito com a modernidade no espaço da cidade. Em virtude disso, no "Prefácio Interessantíssimo", Mário já advertia que

Escrever arte moderna não significa jamais para mim representar a vida actual no que se tem de exterior: automóveis, cinema, asfalto. Si estas palavras freqüentam-me o livro não é porquê pense com elas escrever moderno, mas porque sendo meu livro moderno, elas têm nele sua razão de ser. (ANDRADE, 1993, p. 74) 
Sobre esses elementos presentes nas grandes cidades e na lírica marioadradiana pode-se observar um movimento de oscilação entre aceitar e negar a modernização da cidade. O eu-lírico de Paulicéia é oscilante, ora vê a modernização da cidade como fator positivo, ora questiona essa modernização com certa nostalgia. De acordo com Lafetá (2004, p. 357), o grande problema da obra é "equilibrar a notação subjetiva dos aspectos da cidade moderna com o tumulto de sensações do homem moderno, no meio da multidão".

\section{Notações sensoriais das ruas da Paulicéia Desvairada}

A cidade, símbolo da modernidade, consequência da Revolução Industrial e centro do capitalismo, representa um espaço de transformações. Vista, no primeiro momento, como local de progresso e como possibilidade de um mundo mais justo, a imagem da cidade moderna europeia refletia-se no contexto brasileiro ocasionando interpretações artísticas para os que ousavam decifrá-la. A modernização de São Paulo foi feita com molde nos padrões europeus. Iniciando-se em fins do século XIX, o passado colonial paulistano era destruído para ceder lugar aos novos elementos modernos que possibilitariam uma aproximação entre o cenário urbano brasileiro e o europeu. Todavia, o Brasil não apresentava o mesmo quadro econômico das cidades europeias, por isso, no início do processo de modernização da urbe paulistana, o homem citadino transita entre passado e presente, isto é, vive em um espaço que é ao mesmo tempo moderno e arcaico.

No poema "O Domador", o eu-lírico faz alusão a elementos do passado que se misturam com elementos do presente, deixando transparecer os resquícios provincianos da cidade que se modernizava:

\section{O DOMADOR}

Alturas da Avenida. Bonde 3.

Asfaltos. Vastos, altos repuxos de poeira

Sob o arlequinal do céu oiro-rosa-verde...

As sujidades implexas do urbanismo.

Filets de manuelino. Calvícies de Pensilvânia.

Gritos de goticismo.

$\mathrm{Na}$ frente o tram da irrigação,

Onde um Sol bruxo se dispersa

num triunfo persa de esmeraldas, topázios e rubis...

Lânguidos boticellis a ler Henry Bordeaux

Nas clausuras sem dragões dos torreões... 
Mario, paga os duzentos réis.

São cinco no banco: um branco,

Um noite, um oiro,

Um cinzento de tísica e Mario...

Solicitudes! Solicitudes!

Mas... olhai, oh meus olhos saudosos dos ontens

Esse espetáculo encantado da Avenida!

Revivei, oh gaúchos paulistas ancestramente!

E oh cavalos de cólera sanguínea!

Laranja da China, laranja da China, laranja da China!

Abacate, cambucá e tangerina!

Guardate! Ao aplausos do esfusiante clown,

Heróico sucessor da raça heril dos bandeirantes,

Passa galhardo um filho de imigrante,

Loiramente domando um automóvel!

(ANDRADE, 1993, p. 92).

Nesse poema, o eu-lírico observa, de dentro de um bonde, o espaço urbano em transformação. Mencionando na primeira estrofe os elementos modernos que invadiam a cidade, como os prédios (Alturas da Avenida), os bondes e o asfalto, o eu-lírico, por meio do estilo telegráfico, põe o leitor a imaginar cenas do cotidiano consideradas por ele como "sujidades implexas do urbanismo", que dividem o espaço da rua com o céu arlequinal. Nessa primeira estrofe é possível perceber aspectos do início da modernização, e não a cidade prontamente moderna. Tal fato transparece no segundo verso, pois ao mesmo tempo em que a cidade de São Paulo entra na modernidade, mantém resquício de um passado rural, tendo em vista que algumas partes da cidade são asfaltadas, mas ainda existem ruas com estradas de chão, "Vastos, altos repuxos de poeira", caracterizando a passagem do espaço rural para o urbano.

Nesses versos, percebemos o desenvolvimento acelerado do espaço urbano no qual o cenário da cidade tem o asfalto e os "altos repuxos de poeira", relativos tanto à presença da estrada de chão quanto ao canteiro de obra em que a cidade se tornara, característica que predominou até meados de 1920. Este cenário provinciano passou por uma transformação urbana em consequência da cultura do café no século XIX. Nesta época, São Paulo atraiu a imigração para suprir a mão-de-obra e houve a necessidade de ampliação das ferroviais, pois a cidade passou a ser centro da produção cafeeira.

A produção do cultivo de café foi um dos fatores responsáveis pelo boom demográfico da cidade, pois "entre 1870 e 1880, o estado de São Paulo era o terceiro maior produtor de café do Brasil, responsável por $10 \%$ do total que o país produzia. Em 1890, já era o primeiro, respondendo por mais de 60\% da produção" (FAUSTO, 1989, p. 
193). A cidade, que ainda era provinciana, recebeu entre os anos de 1870 e 1907 mais de dois milhões e trezentos estrangeiros ${ }^{3}$, ocasionando, por consequência, a instalação de indústrias e a urbanização do local, dando início à transformação do espaço urbano.

Vale ressaltar, ainda, que os produtores de café, ou seja, a aristocracia paulistana, constitui a classe social responsável pelo financiamento da Semana de Arte Moderna e da modernização da cidade. Contudo, quando o progresso tecnológico começou a ser instaurado em São Paulo pelos americanos, os produtores de café, assim como os bandeirantes, foram anulados pela cidade que almejava, incessantemente, alcançar o reconhecimento de cidade moderna e, em virtude disso, enaltecia os elementos internacionais, como os automóveis, considerados símbolos da modernidade e do progresso.

A cidade presente no poema "O Domador" se encontra em um momento de expansão econômica, relativa ao que se passava em São Paulo na década de 1920, presenciando o aumento populacional, a modernização e a urbanização, assim como a veemente chegada de imigrantes de várias partes do mundo. Na medida em que São Paulo iniciava esse processo de modernização, conferia à capital um passo para vir a ser uma grande metrópole. E, em meio a essa mudança desenfreada, encontramos o sujeito que vivenciava o processo de modernização e por isso precisava se adaptar aos novos hábitos de vida.

O habitante paulistano encontrava-se em um espaço urbano que ainda não era uma metrópole, mas que já possuía inúmeros elementos modernos de cidades como Paris. Nesse sentido, esse morador da cidade de São Paulo é comparável ao sujeito da metrópole que, como escreveu Simmel (1979, p. 12), "sofre alteração brusca e ininterrupta entre os estímulos exteriores e interiores". As mudanças impõem ao sujeito uma nova postura. O indivíduo citadino é forçado a se adaptar aos novos elementos constituintes da metrópole, dos quais se destacam: a pontualidade, a individualidade, a mercadoria e o dinheiro; fatores que, aos olhos do eu-lírico, faz com que o sujeito se deixe "domar" pelas novas exigências da cidade, as quais dilaceram, aos poucos, as relações humanas.

$\mathrm{Na}$ terceira estrofe, o eu-lírico questiona essas novas exigências da sociedade por meio de um verso irônico, evidenciando que o próprio poeta está sendo domado pela cidade ao ser abordado pelo condutor do bonde: "Mario, paga os duzentos réis". Essa é uma das inúmeras "Solicitudes!", palavra mencionada no quinto verso da terceira estrofe

\footnotetext{
${ }^{3}$ Informações baseadas no livro Em que ano estamos?, de Márcia Camargos.
} 
de maneira enfática e flexionada no plural, para fazer alusão às diversas obrigações concernentes aos sujeitos que vão aparecendo no espaço urbano em consequência das transformações nele ocorridas. Andar de bonde facilitava a locomoção do sujeito, mas, ao mesmo tempo, exigia-lhe uma retribuição simbolizada por uma quantia em dinheiro que não estava ao alcance de grande parcela da população.

Fatores como esse justificam oscilação entre os polos positivo e negativo da modernização, pois ao mesmo tempo em que ela surge como um fator positivo, a facilitação da mobilidade, impõe outra necessidade, a contrapartida financeira. Assim sendo, na quarta estrofe, o eu-lírico aceita a modernização, mas com um tom nostálgico: "Mas... olhai, oh meus olhos saudosos dos ontens". O advérbio usado no plural transmite a ideia de um período de tempo mais longo, e não apenas um dia. Dessa forma, o eu-lírico revela uma sensação de nostalgia, compreensível nos habitantes de uma cidade em transformação.

Todavia, esse saudosismo do passado é minimizado no verso seguinte, segundo verso da quarta estrofe, quando o eu-lírico faz uso do substantivo "espetáculo" e do adjetivo "encantado" para se referir aos acontecimentos sucedidos nas ruas da cidade moderna. Mas, no próximo verso, o sujeito-poético retoma o passado paulistano por meio de uma ordem ao utilizar o verbo reviver no modo imperativo: "Revivei, oh gaúchos paulistas ancestramente!”. Intensificado com a transformação do adjetivo "ancestral” em um advérbio de tempo, "ancestralmente", o eu-lírico faz alusão a um período longínquo, no qual predominava em São Paulo o movimento das bandeiras e o cultivo da agricultura. Com isso, na última estrofe do poema há uma oscilação entre presente e passado, e em ambas as temporalidades existem virtudes e imperfeições.

O poema é finalizado com a imagem do "filho de imigrante,/Loiramente domando um automóvel!", indicando que este alcançou status na sociedade paulistana. O imigrante europeu (Loiramente) é outro elemento representante da modernização de São Paulo. Atraídos pelo sucesso e pela riqueza gerados pela produção cafeeira, vinham para a cidade paulistana em busca de um sonho, o da ascensão social, possível de ser realizado no mundo das grandes fábricas e indústrias. No poema, metonimicamente são eles que fazem uso da tecnologia, pois conquistaram uma posição social elevada na sociedade. Nessa perspectiva, o eu-lírico enfatiza uma dicotomia relacionada à condição social dos imigrantes e a dos bandeirantes. Esses últimos, como os produtores de café, desempenharam importante papel no crescimento de São Paulo. Liderando as bandeiras, expedições organizadas que desbravavam o interior do país, capturando índios para 
realizar trabalho escravo nas terras paulistas, buscando também riquezas minerais, os bandeirantes representam no poema o elemento nacional, enquanto os imigrantes, o elemento internacional. Os bandeirantes, que trabalharam em prol do enriquecimento do Estado, foram, no passado, os grandes “domadores” de São Paulo, mas, no presente, quem doma a cidade são os imigrantes bem sucedidos, que também domam a tecnologia.

Discussões como essa nos permitem observar que na obra de Mário de Andrade há preocupações com questões sociais implicadas no processo de modernização e na consequente substituição do velho pelo novo. Esse posicionamento reforça a negação do autor em ser tachado de futurista, pelo fato de não ser um seguidor dessa corrente antihumanitária, uma vez que Mário vivencia com estranhezas a modernidade. Estruturando modernamente sua lírica, o escritor não faz simples apologia à vida moderna. O que encontramos em seus poemas é uma abordagem do processo de modernização que leva em consideração certos estranhamentos do sujeito diante da nova realidade. Dessa forma, o eu-lírico do poema observa e vivencia o espaço urbano por meio de uma experiência não apenas inovadora, mas também perturbadora. A cidade nos poemas ora está revestida da figura do arlequim audacioso e alegre (representando o progresso da modernização), ora está representando a dilaceração das relações humanas, a hipocrisia, a frivolidade, entre outros. Consequentemente, o eu-lírico ora está alegre ora está triste, e a cidade ora o satisfaz ora não satisfaz. Muitos poemas de Paulicéia Desvairada deixam transparecer o lado negativo da modernização do espaço urbano, sustentando a face maléfica da cidade. Entre eles, podemos destacar

\section{OS CORTEJOS}

Monotonias das minhas retinas...

Serpentinas de entes frementes a se desenrolar...

Todos os sempres das minhas visões! "Bon giorno, caro".

Horríveis as cidades!

Vaidades e mais vaidades...

Nada de asas! Nada de poesia! Nada de alegria!

Oh! os tulmutuários das ausências!

Paulicéia - a grande boca de mil dentes;

e os jorros dentre a língua trissulca

de pus e de mais pus de distinção...

Giram homens fracos, baixos, magros...

Serpentinas de entes frementes a se desenrolar...

Estes homens de São Paulo, todos iguais e desiguais, quando vivem dentro dos meus olhos tão ricos, parecem-me uns macacos, uns macacos.

(ANDRADE, 1993, p. 84) 
Constituído de três estrofes e dezesseis versos, o poema, como o anterior, segue uma estrutura comum à lírica moderna em que a associação das palavras e dos versos não obedece a uma relação puramente discursiva. Essa estrutura dialoga com o fato de o eulírico experimentar simultaneamente várias sensações no espaço da rua. O poema acaba por figurar um espaço polissensorial semelhante ao que definiu Pierre Francastel (1990, p. 229) a respeito do espaço na pintura moderna, "um espaço dotado das dimensões polisensoriais [sic] de nossas experiências íntimas". O conceito fica mais preciso quando observamos o que Francastel escreveu a respeito do quando $A$ dança, de Matisse:

a figuração do espaço deixa de ser uma descrição pitoresca e decorativa para se tornar um registro de gestos ou de ações elementares e de sensações experimentadas no plano da consciência, em função do acordo entre os diferentes sentidos [...]. Figuração espacial moderna, figuração espacial baseada na análise de reflexos, figuração psicofisiológica e não mais óptica no sentido euclidiano do termo (FRANCASTEL, 1990, p. 231).

Em Paulicéia Desvairada, o eu-lírico capta impressões momentâneas e fragmentárias vivenciadas na grande cidade, e se refere à cidade de São Paulo por meio de uma descrição filtrada pelo "eu", ou seja, o sujeito descreve a cidade através de suas sensações interiores e não somente por sua visão óptica. Assim, é possível afirmar que estamos diante de um espaço polissensorial, uma vez que foi através da presença de um corpo com alma na cidade que o eu-lírico construiu uma imagem do que é a Paulicéia Desvairada.

Retomando a leitura de "Os Cortejos", percebe-se que o sujeito moderno sofre com as transformações ocorridas na cidade, uma vez que elas também modificam seu ser. Nessa nova forma de configuração do espaço urbano, o eu-lírico não encontra alegrias nem poesia, pois ambas foram corroídas pelos novos valores sociais que o poeta denomina de vaidades, ou seja, futilidades que corrompem a vivência em sociedade.

A metáfora da cidade de São Paulo como "a grande boca de mil dentes" a triturar homens "fracos, baixos, magros", reduzindo e anulando suas identidades sonoramente na rima entre essas três palavras é uma imagem poderosa. Na última estrofe, o eu-lírico faz referência aos homens paulistanos como seres igualados em suas desigualdades pela dinâmica da cidade e quando vistos pelos olhos do poeta parecem animais imitadores, "uns macacos, uns macacos". Nas ruas da cidade moderna, esses homens "iguais e desiguais" transitam e confundem-se anonimamente. Essa nova realidade citadina pode 
até mesmo destruir a poesia, pois neste espaço tumultuado o poeta não vê "Nada de asas! Nada de poesia! Nada de alegria!”.

Os elementos do mundo moderno, como os automóveis, as luzes, as fábricas, os arranha-céus; ao mesmo tempo em que surgem como inovadores, deslumbrantes, originam a presa, o cansaço, a agitação, a luta pelo dinheiro, a competição, a divisão de trabalho, etc., que são imposições, muitas vezes, cruéis, e se mostram como os motivos das monotonias da retina do poeta. Intensificado pelo advérbio "sempre", tais desvantagens da cidade grande parecem não ter fim, uma vez que são constantes na visão do eu-lírico que cria o neologismo "sempres" para fazer alusão aos contratempos da urbe moderna.

Além de apresentados como recorrentes pelo eu-lírico, os novos costumes da vida moderna estavam sendo aceitos sem contestação pelo morador da urbe, pois como ressaltou Georg Simmel (1979, p. 15), os elementos do mundo moderno "são introduzidos à força na vida pela complexidade e extensão da existência metropolitana", e possuem relação direta com a economia monetária, sistema sem o qual o sujeito moderno não poderia viver. Desse modo, quando o eu-lírico pronuncia "Todos os sempres das minhas visões!", recebe como resposta um simples comprimento: "Bon giorno, caro", evidenciando que o sujeito moderno europeu já estava habituado a viver de acordo com todas as imperfeições da cidade grande apontadas pelo eu-lírico.

Em poemas como esse, e em grande parte dos poemas de Paulicéia Desvairada, a rua, "morada do coletivo", não desempenha mero papel de cenário, é sobretudo espaço vivido, espaço das novas inter-relações modernas. Enquanto elemento central da modernidade, como afirmou Fraya Frehse (2011), a rua é o espaço no qual o eu-lírico vivencia as transformações urbanas, abstraindo desse local público suas impressões que serão materializadas no texto poético. Dito de outra forma, as ruas paulistanas são espaço polissensorial e semantizado, que, como destacou Coelho Neto (2002, p. 118) "recebe referências através e a partir do corpo humano". E é, por excelência, essa experiência corporal urbana que nos transmite as impressões subjetivas da cidade, como no poema seguinte:

\section{RUA DE SÃO BENTO}

Triângulo.

Ha navios de vela para os meus naufrágios!

E os cantares da uiara rua de São Bento... 
Entre estas duas ondas plúmbeas de casas plúmbeas, as minhas delícias das asfixias da alma!

Ha leilão. Há feira de carnes brancas. Pobres arrozais!

Pobre brisas sem pelúcias lisas a alisar!

A cainçalha... A Bolsa... As jogatinas...

Não tenho navios de vela para mais naufrágios!

Faltam-me as forças! Falta-me o ar!

Mas qual! Não ha sequer um porto morto!

"Can you dance the tarantella?" - "Ach! ya."

São as califórnias duma vida milionária

numa cidade arlequinal...

O Clube Comercial... A Padaria Espiritual...

Mas a desilusão dos sombrais amorosos

põe majoration temporaire, $100 \% \mathrm{nt} ! . .$.

Minha Loucura, acalma-te!

Veste o water-proof dos tambéns!

Nem chegarás tão cedo

à fábrica de tecidos dos teus êxtases;

telefone: Além, 3991...

Entre estas duas ondas plúmbeas de casas plúmbeas, vê, lá nos muito-ao-longes do horizonte, a sua chaminé de céu azul!

(ANDRADE, 1993, p.86)

Permeado por um tom descritivo, ainda que subjetivo, nesse poema o eu-lírico anda pela Rua de São Bento registrando imagens dos diversos acontecimentos sucedidos nesse espaço urbano, uma das principais ruas comerciais do centro antigo da cidade, comparada pelo eu-lírico ao canto sedutor da uiara que seduz quem por ali passa. Nesse verso, segundo verso da segunda estrofe, há uma analogia entre a rua (inanimada) e a uiara (animada), sendo que a mãe-d'água representa a rua que seduz os homens para o centro comercial de São Paulo, podendo levá-los ao naufrágio. Dessa forma, as palavras do campo semântico referentes ao mar fazem alusão às tentações do mundo capitalista, como os leilões e as jogatinas.

Em São Paulo, a rua São Bento está localizada no distrito da Sé, no Centro da cidade. Nessa rua movimentada havia leilão e feiras de carnes brancas, que iam aos poucos minimizando o comércio de produtos agrícolas. Endereço da Botica Real, do Grande Hotel, do Café Acadêmico, da Leiteria Campo Belo e do Cine Rosário ${ }^{4}$, locais frequentados pela elite paulistana no século XIX e XX, e uma das entradas do edifício

\footnotetext{
${ }^{4}$ Informações baseadas no livro História da cidade de São Paulo: através de suas ruas, de Antônio Rodrigues Porto.
} 
Martinelli, a rua São Bento representa no poema o centro irradiador do capitalismo, metaforizado pela imagem do mar que possui ondas agitadas, tal como na Califórnia, atraindo e ao mesmo tempo ameaçando as aventuras financeiras do sujeito moderno.

Antes de fazer alusão à rua São Bento, o eu-lírico menciona no primeiro verso $\mathrm{O}$ Triângulo Central. Formado pela Rua São Bento, pela Rua Direita e pela Rua 15 de novembro, esses locais representavam o centro da vida comercial paulistana entre os séculos XIX e XX, e se transformaram rapidamente devido ao desenvolvimento desenfreado da cidade que priorizava o centro de São Paulo.

Na Rua Direita, segundo Antônio Rodrigues Porto (1996), concentravam-se as lojas mais famosas da cidade. Habitada por famílias abastadas, a maioria dos pavimentos térreos das casas da Rua Direita eram destinados às lojas, enquanto na Rua XV de Novembro, local onde as senhoras da aristocracia paulistana exibiam suas joias, roupas e chapéus, "era o local dos escritórios, consultórios, comércios, antes de se definir especificamente como zona bancária” (TOLEDO, 2004, p. 91).

O chamado Triângulo nos remete para a demarcação espacial brasileira, a qual, segundo Roberto Damatta (1997, p. 27), "se faz no sentido de uma hierarquia", isto é, a expressão brasileira "centro da cidade" representa uma superioridade social. Dessa forma, no Triângulo "era onde havia o melhor comércio da cidade, como: Mappin Storea, Casa Alemã, Casa Sloper, Casa dos Três Irmãos, Casa Michel, Au bon Marché, Mappin \& Weber, Casa Lebre, Casa Henrique e outras" (PORTO, 1996, p. 64). Tais espaços demonstram que o sujeito moderno passou a ocupar determinados locais da cidade em função de sua classe social, assim como de sua capacidade produtiva.

Os comerciantes paulistanos, no início do século XX, deram as suas lojas nomes famosos em Paris, tal como a "Louvre Paulista" e "À Pygmalion", localizadas na rua XV de Novembro, "Grand Bazar Parisiennes" e "Au Rendez-Vous de Dames”, na rua São Bento, “Au Bon Diable” e "À La Capitale”, na rua Direta. Apesar de se encontrarem no Brasil, os comerciantes brasileiros e de outras nacionalidades viviam de acordo com a cultura francesa, fazendo uso principalmente do idioma que dominava as publicidades brasileiras em meados de 1900.

No poema "Rua de São Bento", o eu-lírico se pronuncia através de outros idiomas que não o português: "majoration temporaire", para fazer alusão às oscilações do mercado financeiro paulistano, composto por comerciantes de diversas nacionalidades que, além de conquistarem o comércio paulistano, representavam um número significativo entre os funcionários das fábricas da cidade de São Paulo. 
Inserido em uma cidade capitalista, onde o comércio e os jogos introduzem o hábito do consumismo, o eu-lírico declara a necessidade de acalmar-se diante desse contexto financeiro que o torna cada vez mais dependente do dinheiro. Mas, nos últimos versos do poema, este eu-lírico nostálgico transmite mensagens de esperança: "Entre estas duas ondas plúmbeas de casas plúmbeas,/ vê, lá nos muito-ao-longes do horizonte,/ a sua chaminé de céu azul!" (ANDRADE, 1993, p. 86). Apesar da agitação existente no espaço urbano, ainda existe uma chaminé que não impede a visão do céu azul e, mais uma vez, o uso de um advérbio no plural, "muito-ao-longes", tem tom nostálgico. O vocábulo "tambéns", no segundo verso da sexta estrofe, intensifica um fato que acontece mais de uma vez com o sujeito moderno: "Minha Loucura, acalma-te!/Veste o water-proof dos tambéns!". Nesta estrofe, o eu-lírico faz um pedido a si mesmo, solicitando que se aclame, que se faça impermeável e aceite essa maré de sensações inovadoras suscitadas pela modernização no espaço citadino.

Outro elemento recorrente no poema em questão diz respeito à presença de consoantes sonoras em mais de um verso, isto é, a aliteração proporcionada pela consoante surda "s" e pela consoante sonora " $r$ ". Em vinte e cinco versos encontramos setenta e três consoantes "s" e trinta e nove consoantes " $r$ ", pois em versos com dez sílabas poéticas existem oito consoantes "s", por exemplo. A consoante "s" reforça o processo da perda da individualidade, pois a cidade moderna precisa atender a massa, consequentemente, no espaço público da rua, existirão casas, jogatinas $\underline{\text {, navios, }}$

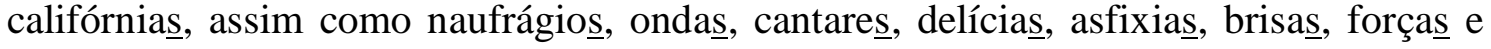
êxtases. Quanto à consoante "r", ainda que com menor intensidade, nos fazem lembrar os movimentos incessantes da cidade moderna, como no poema "Os Cortejos", composto por dezesseis versos nos quais encontramos sessenta e uma consoantes "s" e vinte e três consoantes " $r$ ". No verso "Serpentinas de entes frementes a se desenrolar..." temos onze sílabas poéticas e quatro consoantes "r" que fazem alusão a uma cidade em constante movimento, o qual é intensificado por meio da utilização do ponto de reticências, transmitindo ideia de continuidade.

Tais apontamentos nos direcionam para as considerações a respeito da construção poética feita por Mário de Andrade no "Prefácio Interessantíssimo", no qual o escritor defende que o poema deve ser elaborado com o mínimo de técnica possível, pois o poeta deve se entregar ao impulso lírico. Todavia, essa técnica que deveria anular-se em prol da liberdade de expressão não deixou de existir. 
Ainda sobre o poema "Rua de São Bento", vale destacar a alusão às sensações auditivas e visuais, característica da cidade moderna. O eu-lírico, ao caminhar pela rua, vivencia, em um único período de tempo, o comércio, os anúncios publicitários, o aglomerado de moradias, o trânsito e o grande número de pessoas transitando no espaço público. Dessa forma, a sonoridade dos versos faz alusão à movimentação comercial de São Paulo que interfere diretamente na percepção e na vida do sujeito habitante dessa urbe, que se torna dependente da mercadoria, uma vez que tudo nesse espaço passa a ser vendável, inclusive, o espaço.

\section{Considerações Finais}

Em Paulicéia Desvairada, Mário de Andrade faz alusão às transformações ocorridas nas ruas e nas relações sociais durante o período em que pôde presenciar a modernização da cidade de São Paulo. Observando a modernização de sua cidade no início do século XX, Mário ressaltou, principalmente, a sociabilidade diante das modificações avassaladoras que surtiam efeito direto na vida do paulistano.

Sem se deter na descrição minuciosa do espaço urbano da cidade, o poeta, por meio da lírica moderna, expõe sensações do eu-lírico experimentadas nas ruas de uma São Paulo desvairada. O eu-lírico dos poemas percebe as ruas paulistanas inserindo-se no espaço com corpo e alma, intercalando estímulos exteriores e interiores, presente e passado. Sua poesia problematiza a cidade moderna e seus aspectos sociais, aberto ao novo, mas, também, com saudade do que ia ficando para trás. Daí o tom nostálgico em muitos poemas da obra.

Aderindo à lírica moderna, Mário, ao mesmo tempo, celebra e crítica a cidade em que São Paulo estava se transformando. A grande boca de mil dentes, a metrópole do trabalho e do dinheiro, que apequena e despersonaliza quem nela circula, era tanto sedutora como amedrontadora. Mas que a leitura da lírica moderna de Pauliceia Desvairada não nos engane pensando que seduz pela incomunicabilidade, como destacou Hugo Friedrich sobre a dissonância da lírica moderna. Na leitura que propomos aqui consideramos os poemas impactantes na medida em que o eu-lírico busca aludir com a linguagem às sensações percebidas no espaço urbano. $O$ poema pode parecer, no primeiro momento, incomunicável, mas só para quem de fato não se aventurar pelas ruas de seus versos. A São Paulo que é a comoção da vida do eu-lírico é uma imagem moderna complexa, ao mesmo tempo cosmopolita e brasileira. "É uma imagem apologética e crítica. Isto é, ao mesmo tempo é um elogio da cidade e uma crítica de seus aspectos. Mas 
o tom geral da Paulicéia é de euforia, de otimismo”. (LAFETÁ, 1997, p. 89). Para nós, o

leitor tem a liberdade de escolher se se apega mais aos elogios ou à nostalgia.

Por fim, destacamos que a lírica de Mário de Andrade associa sentimentos individuais a sentimentos universais. O eu-lírico que transita pelas ruas de São Paulo, tanto se alegra quanto se entristece com a modernidade, além disso, ele critica os resultados dessa modernidade por ele presenciados como verdadeiro tupi que tange alaúde.

\section{Referências}

ANDRADE, Mário de. Poesias completas. Edição crítica de Diléia Zanotto Manfio. Belo Horizonte: Villa Rica, 1993.

BAUMAN, Zygmunt. Confiança e medo na cidade. Trad. Eliana Aguiar. Rio de Janeiro: Jorge Zahar, 2009.

CAMARGOS, Márcia. Em que ano estamos? Ilustrações Rodrigo Rosa. São Paulo: Companhia das Letras: 2004.

COELHO NETO, J. T. A construção do sentido na arquitetura. São Paulo: Perspectiva, 2002.

DAMATTA, Roberto. Espaço: Casa, Rua e outro Mundo: O Caso do Brasil. In: A Casa \& a Rua: Espaço, Cidadania, Mulher e Morte no Brasil. Rio de Janeiro: Rocco, 1997. FAUSTO, Bóris. "Expansão do café e política cafeeira". In: FAUSTO, Bóris (Org.). História geral da civilização brasileira III. O Brasil republicano. Rio de Janeiro: Bertand, 1989, p.193-249.

FRANCASTEL, Pierre. Pintura e sociedade. Trad. Elcio Fernandes. São Paulo: Martins Fontes, 1990.

FRIEDRICH, Hugo. A estrutura da lírica moderna. São Paulo: Duas cidades, 1978.

FREHSE, Fraya. Ô da rua!: o transeunte e o advento da modernidade em São Paulo. São Paulo: Edusp, 2011.

GOMES, Renato Cordeiro. A cidade, a literatura e os estudos culturais: do tema ao problema. Ipotesi - Revista de Estudos Literários. Juiz de Fora, v.3 - n.2, p.17-30, jul./dez. 1999.

LAFETÁ, João Luiz. A dimensão da noite e outros ensaios. São Paulo: Duas cidades, 2004.

LAFETÁ, João Luiz. “A representação da cidade de São Paulo em dois momentos da poesia de Mário de Andrade". In: SILVA, Lúcia Neíza Pereira da. Mário universal paulista. São Paulo: SMC: Departamento de Bibliotecas Públicas, 1997, p.85-95.

PORTO, Antônio Rodrigues. História da cidade de São Paulo: através de suas ruas.

São Paulo: Carthago Editorial, 1996.

SIMMEL, Georg. A Metrópole e a Vida Mental. In: Velho, Otávio Guilherme (org.), O Fenômeno Urbano. $4^{\text {a }}$ ed. Rio de Janeiro: Zahar Editores, 1979, p.11-25.

TOLEDO, Benedito Lima de. São Paulo: três cidades em um século. São Paulo:

Cosac \& Naif, 2004

Data de Recebimento: 15/06/2020

Data de Aprovação: 16/01/2021 


\title{
Para citar essa obra:
}

CUNHA, Bruna Araujo; SIQUEIRA, Joelma Santana, Notações sensoriais do espaço urbano em Paulicéia Desvairada (1922), de Mário de Andrade In: RUA [online]. Volume 27, número 1 - p. 117-130 - e-ISSN 2179-9911 - Junho/2021. Consultada no Portal Labeurb - Revista do Laboratório de Estudos Urbanos do Núcleo de Desenvolvimento da Criatividade. http://www.labeurb.unicamp.br/rua/

Capa: cruzamento da São Bento com a rua Direita. Disponível em: https://saopauloesuasruas.wordpress.com/2015/05/13/rua-sao-bento/comment-page-1/

\author{
Laboratório de Estudos Urbanos - LABEURB \\ Núcleo de Desenvolvimento da Criatividade - NUDECRI \\ Universidade Estadual de Campinas - UNICAMP \\ http://www.labeurb.unicamp.br/ \\ Endereço: \\ LABEURB - LABORATÓRIO DE ESTUDOS URBANOS \\ UNICAMP/COCEN / NUDECRI \\ CAIXA POSTAL 6166 \\ Campinas/SP - Brasil \\ CEP 13083-892 \\ Fone/ Fax: (19) 3521-7900 \\ Contato: http://www.labeurb.unicamp.br/contato
}

